Research paper

\title{
Phenotypic variability confirmed by nuclear ribosomal DNA suggests a possible natural hybrid zone of Triatoma brasiliensis species complex
}

\author{
Jane Costa ${ }^{\mathrm{a}, *}$, Maria Dolores Bargues ${ }^{\mathrm{b}}$, Vanessa Lima Neiva ${ }^{\mathrm{a}}$, Gena G. Lawrence ${ }^{\mathrm{c}}$, Marcia Gumiel ${ }^{\mathrm{d}}$, \\ Genova Oliveira ${ }^{\mathrm{e}}$, Pedro Cabello ${ }^{\mathrm{f}}$, Marli Maria Lima ${ }^{\mathrm{g}}$, Ellen Dotson ${ }^{\mathrm{c}}$, David William Provance Jr ${ }^{\mathrm{h}}$, \\ Carlos Eduardo Almeida ${ }^{\mathrm{i}, * *}$, Lucia Mateo ${ }^{\mathrm{b}}$, Santiago Mas-Coma ${ }^{\mathrm{b}}$, Jean Pierre Dujardin ${ }^{\mathrm{j}}$ \\ a Laboratório de Biodiversidade Entomológica,Instituto Oswaldo Cruz, Rio de Janeiro, RJ, Brazil \\ b Dep. de Parasitología, Facultad de Farmacia, Univ. de Valencia, Burjassot, Valencia, Spain \\ c Entomology Branch, Div. Parasitic Diseases, CDC, Atlanta, GA, USA \\ d Laboratório de Fisiologia e Bioquímica de Insetos Instituto Oswaldo Cruz, Rio de Janeiro, RJ, Brazil \\ e Secretaria de Vigilância em Saúde, Pernambuco, Brazil \\ ${ }^{\mathrm{f}}$ Laboratório de Genética Humana, Instituto Oswaldo Cruz, Rio de Janeiro, RJ, Brazil \\ ${ }^{g}$ Laboratório de Eco-epidemiologia da Doença de Chagas, Instituto Oswaldo Cruz, Rio de Janeiro, RJ, Brazil \\ ${ }^{\text {h } C e n t r o ~ d e ~ D e s . ~ T e c n o l o ́ g i c o ~ e m ~ S a u ́ d e / F i o c r u z, ~ C D T S, ~ R i o ~ d e ~ J a n e i r o, ~ R J, ~ B r a z i l ~}$ \\ ${ }^{i}$ Univers. Est. Paulista Júlio de Mesquita Filho, Araquara, SP, Prog. de Pós-Graduação em Ecologia e Monitoramento Ambiental (PPGEMA), UFPB, Campus IV, Paraíba, Brazil \\ j Institute de Recherche pour le Development, Montpelier, France
}

\section{A R T I C L E I N F O}

\section{Article history:}

Received 15 June 2015

Received in revised form 7 October 2015

Accepted 24 October 2015

Available online 28 October 2015

\section{Keywords:}

Triatominae

Phenotype

Speciation

Hybridization

Epigenetics

\begin{abstract}
A B S T R A C T
Triatoma brasiliensis macromelasoma occurs in Pernambuco state, Brazil, which is situated between the distribution areas of Triatoma brasiliensis brasiliensis (north) and Triatoma juazeirensis (south). T. b. macromelasoma displays greater variations in its chromatic phenotype than either T. b. brasiliensis or T. juazeirensis, and patterns reminiscent of one or the other. Experimental crosses from each of these members of the $T$. brasiliensis species complex generated fertile offspring suggesting that viable hybrids could be present in nature, despite their significant genetic distances. Considering the geographical position of occurrence of the T. b. macromelasoma (in Pernambuco) it was proposed to be an area capable of supporting natural hybridization between $T$. $b$. brasiliensis and T. juazeirensis. Since phenotypic variability is expected, this study investigated the existence of intermediate chromatic phenotypes for $T$. b. macromelasoma in various locations in areas between the $T$. b. brasiliensis and $T$. juazeirensis occurrences. Thirteen different color patterns were for the first time characterized and nine of those displayed intermediate phenotypes. Molecular analysis performed using ribosomal DNA intergenic region, grouped all within the T. brasiliensis complex. The intermediate chromatic phenotypes, molecular analysis and experimental crosses all support the distinction of a zone of hybridization that gave rise to the $T$. b. macromelasoma through homoploidal evolution.
\end{abstract}

(c) 2015 Elsevier B.V. All rights reserved.

\section{Introduction}

The origin and significance of phenotypic variations within groups of insects is not well understood despite numerous references in the literature. In the Triatominae subfamily, several species have been described with wide variations including: Triatoma rubrovaria (Blanchard, 1843), Triatoma pseudomaculata Corrêa and Espínola,

\footnotetext{
* Correspondence to: J. Costa, Av. Brasil, 4365 Pav. Mourisco 202, Manguinhos, 21045900 Rio de Janeiro, RJ, Brazil.

** Correspondence to: C.E. Almeida, Rua da Mangueira, s/n, Campus IV (Litoral Norte), UFPB, 58297000 Rio Tinto, PB, Brazil.

E-mail addresses: jcosta@ioc.fiocruz.br (J. Costa), almeida_ce@hotmail.com (C.E. Almeida),
}

1964, Panstrongylus geniculatus Latreille, 1811 and Triatoma dimidiata (Latreille, 1811). These variations in appearance can underscore multiple changes in the taxonomic status (see Lent and Wygodzinsky, 1979, Almeida et al., 2002). The case of Triatoma infestans melanosoma Martínez, Olmedo and Carcavallo, 1987, is illustrative. It was initially considered to belong to one species (Lent and Wygodzinsky, 1979), but was later validated as a separate species, Triatoma melanosoma, based only on color patterns (Lent et al., 1994). In the argumentation, the genital structures were not retained since Triatoma infestans (Klug, 1834) is known to exhibit intraspecific variations (Pires et al., 1995). Subsequently, an analysis of mitochondrial DNA sequences using the Cyt B gene showed no differences between them suggesting that T. melanosoma was indeed a dark morphotype of T. infestans (Monteiro et al., 1999). Additionally, geometric morphometrics analyses synonymized T. melanosoma, confirming that it was a dark morphotype of $T$. infestans, since size and shape 
variations were of the same order as geographic variation in T. infestans. This finding was in complete agreement with the molecular analyses previously carried out (Gumiel et al., 2003).

The lack of research on the distribution and characterization of the chromatic variations of $T$. $b$. brasiliensis Neiva, 1911, as mentioned by Lent and Wygodzinsky (1979), has led to multidisciplinary approaches that examined geographic distributional patterns, morphological, biological, ecological and molecular biology aspects and geometric morphometrics (Costa et al. 1997a,b, 1998, 2002, 2003a, b, 2009, 2014; Monteiro et al., 2004; Neiva-Lima et al., 2012, Correia et al., 2013). Those approaches revealed that the distinct chromatic variations mentioned by Lent and Wygodzinsky (1979) were indeed members of the $T$. brasiliensis species complex which is currently composed of three species and two subspecies. Here we summarize the taxonomic updates of the five members of the group according to Costa and Felix (2007) and Costa et al. (2006, 2013): T. b. brasiliensis Neiva 1911, T. b macromelasoma Galvão, 1956, Triatoma melanica Neiva \& Lent, 1941, T. juazeirensis Costa and Felix, 2007 and T. sherlocki Papa et al., 2002.

The use of multidisciplinary approaches has improved the classification of the Triatominae group and also of the insects in general. Classifications independent of morphology provided an opportunity to study the phenotypic variability and polymorphisms within a species of insects and to examine the evolutionary process (Gumiel et al., 2003; Pacheco et al., 2003, 2007; Adams et al., 2009; Costa et al., 2013). As a result, it was suggested that T. b. macromelasoma, arose through homoploidal hybridization. This hypothesis was proposed based on color patterns and morphological traits such as egg size and wing shape (Costa et al., 2009). The hypothesis was further supported by the study of distribution patterns and ecological modeling (Costa et al., 2002, 2014). While the available molecular data (Costa et al., 1997b; Monteiro et al., 2004) was not conclusive, it did not refute the possibility of hybrid speciation. This scenario suggests that $T$. b. macromelasoma was the product of crosses between $T$. b. brasiliensis and T. juazeirensis within sites located in the state of Pernambuco (PE), which covers an area between the distributions of T. b. brasiliensis (in the north) and T. juazeirensis (in the south) and encompasses the natural range of $T$. $b$. macromelasoma (Costa et al., 2009, 2014).

Given the importance of members of the $T$. brasiliensis complex in the occurrence of Chagas disease (Silveira and Vinhaes, 1999; Costa et al., 2003a; Almeida et al., 2008), ribosomal DNA (rDNA) characterization and verification of phenotypic variability are important aspects for the precise identification of the species vectors bringing support for the more accurate measures for disease control. Furthermore, domiciles in the state of PE exhibit a high incidence of infestation by several species of triatomines (Costa et al., 2003a) making the state of PE an area strategically located to better understand the phenotypic variability of the members of the T. brasiliensis complex. Here we present the analysis of field collections of triatomines from various locations within the state of PE using a multidisciplinary approach. Despite the relative genetic distances between the proposed parental species of $T$. b. macromelasoma, the results of Costa et al. (2009) are consistent with the observed laboratory hybridization of $T$. $b$. brasiliensis and T. juazeirensis (Costa et al., 2003b) and suggest the possibility that T. $b$. macromelasoma evolved through homoploidal hybridization.

The present paper investigates the existence of intermediate chromatic phenotypes for T. b. macromelasoma collected from natural and artificial ecotopes in various locations between the distributions of $T$. b. brasiliensis and T. juazeirensis and examines their relationships with genetic variation, based on the complete rDNA region including ITS-1, 5.8S and ITS-2.

\section{Materials and methods}

\subsection{Collection of specimens}

Collections were carried out in fifteen counties that were chosen according to the records of domicile infestations in the state of PE from the Secretary of Health Surveillance (SVS). Collection points were distributed within three geographical areas: of "Sertão do Araripe", "Sertão do São Francisco" and "Agreste". Fig. 1 shows the geographical spots where bugs were collected, along with the number of phenotypes and number of specimens collected at each collection point. Collections were performed individually during the day with the aid of forceps and each captured triatomine was placed into small vials containing filter paper. In some instances, Pirisa $(5 \mathrm{~mL} / 500 \mathrm{~mL}$ water) was utilized to dislodge insects from inaccessible spaces. Home environments, peridomestic spaces and sylvatic areas were searched using the same procedures described by Costa et al. (1998). Part of the collected specimens were identified and deposited in the Entomological Collection of Instituto Oswaldo Cruz, in the section Lima-Neiva \& Costa of Triatominae collection and the remaining were kept in alcohol for additional studies.

\subsection{Identification and characterization}

Only adult insects were examined alive on a stereoscopic microscope (Zeiss Stemi SV6) and the specimens were categorized according to the standards proposed by Lent and Wygodzinsky (1979), Galvão (1956), and Costa et al. (2013). All observed patterns were photographed and included into a Table 1 of color variations based on the general color of the insect, as well as the bands on the prothorax and legs, independently from the location of collection. Latter, the patterns of coloration were linked to the sites of collection (Supplementary Fig. 1).

\subsection{Phenetic analyses}

The chromatic variation was converted into a presence-absence table using characters related to the colors and their observed patterns. This table allowed for a quantitative estimation of phenetic distances between color patterns, as derived from the following similarity indexes: the Jaccard, the Hamann, the Rogers-Tanimoto and the Sokal-Michener indexes. Binary distances were then tested for their correlation with corresponding evolutionary distances (Tajima and Nei, 1984) using a Mantel test (10,000 iterations). A descriptive test of hybridization hypothesis was undertaken by examining the chromatic phenotypes in relation to various locations between the areas of distribution of $T$. $b$. brasiliensis and T. juazeirensis.

\section{4. rDNA sequence analyses}

The complete sequences of ITS-1, 5.8S and ITS-2 comprising the whole intergenic region of rDNA of 28 specimens representing all members and different chromatic patterns of the $T$. brasiliensis complex were analyzed (Table 2). Two legs for representative specimens of the main phenotypes were used and processed individually for DNA extraction using methods outlined before (Bargues et al., 2006). This intergenic region was amplified using primers Lim1657 and 28T, designed in conserved positions of $18 \mathrm{~S}$ and $28 \mathrm{~S}$ rRNA genes, previously described (Bargues and Mas-Coma, 1997; Marcilla et al., 2001; Bargues et al., 2006). Amplification procedures and thermal cycler conditions were carried out in a Mastercycler EP gradient (Eppendorf, Hamburg, Germany), by 30 cycles of $30 \mathrm{~s}$ at $94^{\circ} \mathrm{C}$, $30 \mathrm{~s}$ at $50-55^{\circ} \mathrm{C}$ and $1 \mathrm{~min}$ at $72^{\circ} \mathrm{C}$, preceded by $30 \mathrm{~s}$ at $94^{\circ} \mathrm{C}$ and followed by $7 \mathrm{~min}$ at $72{ }^{\circ} \mathrm{C}$. Ten $\mu$ of each PCR product were checked by staining with ethidium bromide on $1 \%$ Nusieve ${ }^{\circledR}$ GTG agarose (FMC) gel electrophoresis, using the Molecular Weight Marker VI (Boehringer Mannheim) at $0.1 \mu \mathrm{g} D \mathrm{DN} / \mu \mathrm{l}$ as control. Primers and nucleotides were removed from PCR products by purification using Ultra Clean ${ }^{\mathrm{TM}}$ PCR Clean-up DNA Purification System (MoBio, Solana Beach, CA, USA) according to the manufacturer's protocol and resuspended in $50 \mu \mathrm{l}$ of $10 \mathrm{mM}$ TE buffer (pH 7.6). The final DNA concentration was determined by measuring the absorbance at 260 and $280 \mathrm{~nm}$. The sequencing of the complete intergenic region was performed on both strands by the dideoxy chaintermination method. It was carried out with the Taq dye-terminator 


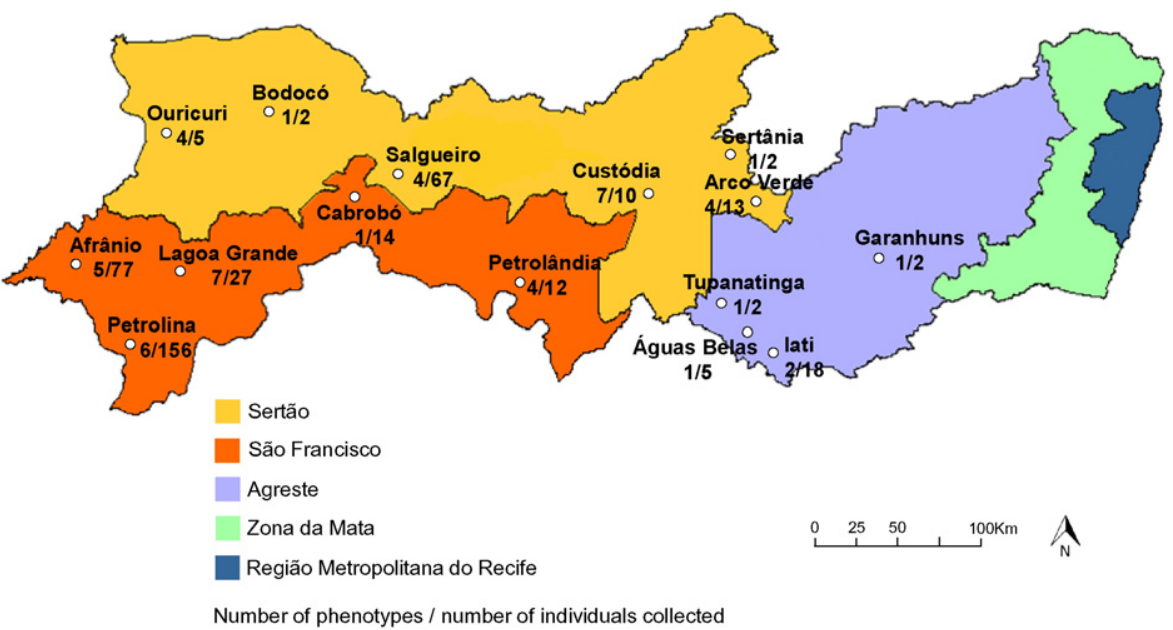

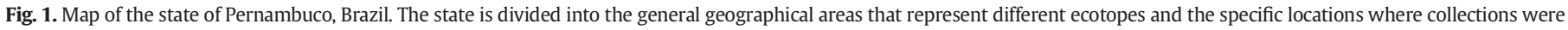
performed. Source: www.pernambuco.gov.br. Number of phenotypes/number of specimens collected in each locality is reported in parentheses.

chemistry kit for the sequencers $\mathrm{ABI} 3130$ and $\mathrm{ABI} 3700$ (Applied Biolsystems, CA, USA), using PCR primers. Given the importance of the recent discovery of a pseudogenic $5.8 \mathrm{~S}$ + ITS-2 sequence, designed as "ps(5.8S + ITS-2)", widely distributed in triatomines of North, Central and South America (Bargues et al., 2014), special efforts were made to ensure that no double signal was present in the chromatograms, in the way to confirm that variable positions in the intergenic region were not due to an underlying paralogous sequence. The haplotype $(\mathrm{H})$ terminology used for both ITS follows the nomenclature for composite haplotyping $(\mathrm{CH})$ previously proposed (Bargues et al., 2006; Mas-Coma and Bargues, 2009). Accordingly, ITS-2 haplotypes are noted by numbers and ITS- 1 haplotypes are noted by capital letters.

\subsection{Sequence alignment, length and AT-content and similarity/identity matrix}

Sequences were aligned with CLUSTAL W2 (Larkin et al., 2007), using default parameters, including corresponding penalties for gaps in pairwise and multiple alignments. The NCBI BLAST (Basic Local Alignment Search Tool, http://blast.ncbi.nlm.nih.gov/Blast.cgi) was used for sequence comparison against the GenBank database. Length and AT-content of each one of the markers including in the complete intergenic rDNA region was determined using MEGA 5.2 program (Tamura et al., 2011). Sequence divergence within and among different ITS- 1 and ITS- 2 sequence types were measured using total character differences, including all possible changes, transitions (ts), transversions (tv) and insertions/deletions (indels) as character states in PAUP 4.0b10 (Swofford, 2002). The MatGAT (Matrix Global Alignment Tool) software has been used to calculate identity/similarity between every pair of sequences using the Myers and Miller global alignment algorithm (Myers and Miller, 1988).

\subsection{Phylogenetic and network analyses}

A phylogenetic network estimation using median-joining or $\mathrm{MJ}$ network algorithm using default parameters (equal character weight $=$ 10 , transitions/transversions weight $=1: 1$, and connection cost as a criterion) was constructed, for the ITS- 1 and ITS-2 combined haplotypes, using Network 6.4.1.1 (http://www.fluxus-engineering.com/). Hypothetical median vectors were added to the network for shortest connection between the data set. Phylogenetic trees were inferred using the Maximum Likelihood (ML) and distance-based (Neighbor Joining) (NJ) methods implemented in PAUP 4. ML parameters and the evolutionary model best fitting our dataset were determined using Akaike information criteria (AIC) (Akaike, 1974; Posada and Buckley, 2004), implemented in jModeltest version 0.1.1 (Posada, 2008). The evolutionary distances were computed using the Tajima-Nei method (Tajima and Nei, 1984). Starting branch lengths were obtained using the least-squares method with ML distances. To provide an assessment of the reliability of the nodes in trees, statistical support was evaluated with 1000 bootstrap pseudoreplicates, using NJ search, with fast stepwise pseudoreplicates (random sequence addition replication) and heuristic search with nearest-neighbor-interchange (NNI) approach.

\section{Results}

\subsection{Collected specimens}

A total of 412 triatomine specimens were collected with 286 from the area "Sertão do São Francisco", 99 from the region of "Sertão do Araripe" e and 27 from the "Agreste" (Fig. 1).

3.2. Chromatic phenotypes for T. b. macromelasoma and members of the T. brasiliensis complex collected in PE

The triatomine specimens displayed numerous color variations, especially in the thorax and legs. The general color of the body, along with the color and specific patterns on the prothorax and legs, were used to categorize the specimens into thirteen color patterns independently from their collection site. Each of the thirteen patterns was assigned names, which refer to the color characteristics and the species of the $T$. brasiliensis complex it most closely resembles. Two of the chromatic patterns are similar to those of $T$. juazeirensis and $T$. $b$. macromelasoma, nine patterns were consistent with patterns intermediate to members of the $T$. brasiliensis complex and two patterns showed no similarities with members of the $T$. brasiliensis complex or an intermediate pattern. A description of each color pattern is presented in Table 1.

Fig. 2a shows representative images of examples for T. b. brasiliensis, $T$. b. macromelasoma and T. juazeirensis, members of the T. brasiliensis complex. Examples of ten of the determined thirteen color patterns are shown in Fig. 2b. The predominant feature observed for $T$. $b$. brasiliensis was the presence of a ring on the appendages, which was used to determine the categories that were intermediate. The intermediates of T. b. macromelasoma used the shape of the longitudinal stripe on the pronotum as an indicator. For T. juazeirensis, the general dark color pattern was consistent with intermediate patterns.

After the determination of the various color patterns, the collection of triatomines was tabulated based on collection site and the chromatic phenotype (Supplementary Fig. 1). From the data, the total number of 
Table 1

Different phenotypes of Triatoma brasiliensis collected in Pernambuco state, Brazil. Descriptions are based on the general color of the insect, as well as the bands on the prothorax and legs.

\begin{tabular}{|c|c|}
\hline $\begin{array}{l}\text { Color } \\
\text { pattern }\end{array}$ & Description \\
\hline Juaz & $\begin{array}{l}\text { General color pattern of black with a black pronotum and black } \\
\text { appendages; as described by Costa and Felix (2007) }\end{array}$ \\
\hline & $\begin{array}{l}\text { General color pattern of black with a black pronotum and appendages } \\
\text { marked with clear spots that do not form rings; or General color }\end{array}$ \\
\hline Mac/juaz & $\begin{array}{l}\text { pattern of black with a pronotum marked with narrow yellow bands } \\
\text { reaching the anterior lobe, but not past the posterior margin of the } \\
\text { posterior lobe. The appendages are black; }\end{array}$ \\
\hline Mac & $\begin{array}{l}\text { General color pattern of a dark yellow with a pronotum marked with } \\
\text { narrow bands the extend to the anterior lobe, but not a part of the } \\
\text { posterior margin of the posterior lobe. The appendages have pale spots } \\
\text { that do not form distinct rings; }\end{array}$ \\
\hline $\mathrm{Mac} / \mathrm{bn}$ & $\begin{array}{l}\text { General color pattern of brown with a pronotum marked with narrow } \\
\text { yellow bands reaching the anterior lobe, but not past the posterior } \\
\text { margin of the posterior lobe. The appendages have clear spots that do } \\
\text { not form rings; or General color pattern of brown with a brown } \\
\text { pronotum and appendages marked with clear spots that do not form } \\
\text { rings; }\end{array}$ \\
\hline $\mathrm{Bras} / \mathrm{mac}$ & $\begin{array}{l}\text { General color pattern of dark yellow with a pronotum marked with } \\
\text { yellow longitudinal bands extending outward from the median carinae } \\
\text { in the posterior margin of the posterior lobe to the closed region of the } \\
\text { anterior lobe. The appendages have pale spots that do not form distinct } \\
\text { rings; or General color pattern of dark yellow with a pronotum marked } \\
\text { with narrow yellow longitudinal bands reaching the anterior lobe, but } \\
\text { not parting the posterior margin. The appendages have bright spots } \\
\text { that form a sharp ring; }\end{array}$ \\
\hline Dark bras & $\begin{array}{l}\text { General color pattern of black with a pronotum marked with yellow } \\
\text { longitudinal bands extending from the carinae at the posterior margin } \\
\text { of the posterior lobe until the closed anterior lobe. Appendages have a } \\
\text { sharp ring in the middle; }\end{array}$ \\
\hline Brown & $\begin{array}{l}\text { General color pattern of brown with a light brown pronotum and light } \\
\text { brown appendages; }\end{array}$ \\
\hline Juaz mcfp & $\begin{array}{l}\text { General color pattern of black with a pronotum displaying small pale } \\
\text { spots on the prothorax. The appendages are black; }\end{array}$ \\
\hline $\begin{array}{l}\text { Light } \\
\text { brown }\end{array}$ & $\begin{array}{l}\text { General color pattern of light brown with a light brown pronotum and } \\
\text { light brown appendages; }\end{array}$ \\
\hline $\mathrm{Bn} \mathrm{cc}$ & $\begin{array}{l}\text { General color pattern of brown with a brown pronotum, but a carinae } \\
\text { without color. The appendages are brown; }\end{array}$ \\
\hline Bras/bn & $\begin{array}{l}\text { General color pattern of brown with a pronotum marked with yellow } \\
\text { longitudinal bands extending from the carinae at the posterior margin } \\
\text { of the posterior lobe until the closed anterior lobe. Appendages have a } \\
\text { sharp ring in the middle; }\end{array}$ \\
\hline $\begin{array}{l}\mathrm{Mac} / \mathrm{lt} . \\
\mathrm{bn}\end{array}$ & $\begin{array}{l}\text { General color pattern of light brown with a pronotum marked with } \\
\text { narrow yellow bands reaching the anterior lobe, but not past the } \\
\text { posterior margin of the posterior lobe. The appendages are marked } \\
\text { with clear spots that do not form rings; }\end{array}$ \\
\hline Bras/juaz & $\begin{array}{l}\text { General color pattern of black with a pronotum marked with yellow } \\
\text { longitudinal bands extending from the median carinae of the posterior } \\
\text { margin of the posterior lobe until the closed region of the anterior } \\
\text { lobe. The appendages are black. }\end{array}$ \\
\hline
\end{tabular}

Juaz.: form similar to T. juazeirensis; mac/juaz.: form intermediate between $T$. $b$. macromelasoma and T. juazeirensis; mac.: form similar to T. b. macromelasoma; mac/bn.: form intermediate between the T. macromelasoma and the Brown form; bras/mac.: form intermediate between $T$. b. brasiliensis and T. macromelasoma; dark/bras.: Intermediate form of dark T. b. brasiliensis; bn.: Brown; juaz mcfp.: form similar to T. juazeirensis with thin pale spots on prothorax; It. bn.: Light Brown; bn.cc.: Brown with a clear carinae; bras/ bn.: Intermediate form between T. b. brasiliensis and the Brown form; mac/It.bn.: form intermediate between T. macromelasoma with Light Brown; bras/juaz.: form intermediate between $T$. b. brasiliensis and T. juazeirensis.

triatomines for each chromatic phenotype was plotted based on the geographical region of its collection (Supplementary Fig. 2). The greatest number of triatomines was collected within the São Francisco region consisting predominantly of the mac/juaz phenotype followed in decreasing order by the mac, juaz and mac/bn chromatic patterns. The region of Sertão Araripe yielded a greater number of $\mathrm{mac} / \mathrm{bn}$. The least number of specimens were collected in the Agreste region consisting of only the dark bras and bras/mac phenotypes.

The distribution of triatomines within each area was not uniform. In the São Francisco regions, greater one half of the collections occurred around the Petrolina metropolitan area and together with the Afranio area accounted for $81 \%$ of the samples collected. Of those, $55 \%$ displayed chromatic characteristics reminiscent of $T$. juazeirensis, which is consistent with their proximity to the northern boundary of the distribution of T. juazeirensis. In the north of Pernambuco, the preponderance of collection came from around the Salgueiro metropolitan area and 88\% were observed with patterns consisting of a brown phenotype. All of the triatomines collected in the Agreste region displayed chromatic patterns similar to $T$. b. brasiliensis.

\subsection{Ribosomal DNA sequence analyses}

\subsubsection{Complete intergenic rDNA sequence}

The complete intergenic region revealed the existence of 16 combined haplotypes ( $\mathrm{CH}$ ) (Table 2). Their length and AT content ranged between 1468 and $1475 \mathrm{bp}$ (mean, $1471.61 \mathrm{bp}$ ) and 65.10\% and 65.36\% (65.23\%), respectively. The alignment of the $16 \mathrm{CH}$ generated a $1475 \mathrm{bp}$ dataset which contained 33 variable positions (2.23\%) of which 7 were singleton sites $(0.47 \%), 15$ parsimony informative positions (1.17\%) and 11 indels (0.74\%) (Table 3). The $5.8 \mathrm{~S}$ gene had a length of $155 \mathrm{bp}$ and an AT content of $41.94 \%$ and was identical in all specimens analyzed. A similarity/identity matrix was generated for the calculation of the similarity and identity between every pair of sequences in the data set including $16 \mathrm{CH}$. Maximum similarities/identities (99.9\%) were obtained between $\mathrm{CH}$ of $T . b$. brasiliensis and T.b. macromelanosoma while the less similarity were obtained between T. melanica and T. b. brasiliensis-3A (98.8\%); T. melanica and T. juazeirensis (98.8\%) and T. b. brasiliensis vs T. melanica, T. sherlocki or T. juazeirensis (average, 98.6\%) (Supplementary Table 1).

\subsection{First internal transcribed spacer ITS-1}

A total of 14 different ITS-1 haplotypes were detected among the samples analyzed and codified as ITS1-A to ITS1-N. Length and AT content ranged between 836 and 837 bp ( 836.9 bp) and 61.89\%$62.20 \%(62.04 \%)$, respectively. Nine of them correspond to T. $b$. brasiliensis and T. b. macromelanosoma (haplotypes ITS1-A to ITS1-I) (Tables 2,3$)$. Seven polymorphic sites $(0.84 \%)$ appear in the alignment of $T$. $b$. brasiliensis (ITS1-A,B,C) and T. b. macromelanosoma (ITS1A,D,E,F,G,H,I) haplotypes. These nine haplotypes representing both subspecies, show a range of 1-4 (average of 2.1) nucleotide differences in their respective pairwise sequence comparisons. Haplotype ITS1-J was detected in samples of T. melanica; haplotypes ITS1-K and ITS1-L in samples of T. sherlocki and haplotypes ITS1-M and ITS1-N in samples of $T$. juazeirensis (Tables 2, 3). Haplotype ITS1-J differ in only one mutation in comparison with haplotypes ITS1-K and ITS1-L (positions 229 and 808 , respectively of their respective alignment - Table 3). Supplementary Table A and Supplementary Table B show pairwise distances between all sequenced specimens of $T$. brasiliensis members by using combined (ITS-1 + ITS-2) haplotypes.

In the 837 bp-long alignment including the 14 ITS- 1 haplotypes representing the members of the $T$. brasiliensis complex analyzed, 22 variable positions appeared (2.63\%) of which, 21 were substitutions (2.51\%), including 15 parsimony-informative positions and 6 singleton sites, and one (0.12\%) gapped position (Table 3$)$.

Sequence analysis comparison allows the distinction of three ITS-1 haplogroups corresponding to T.b. brasiliensis + T. b. macromelanosoma; T. melanica $+T$. sherlocki; and T. juazeirensis. Average number of absolute differences and p-distances between these haplogroups ranged between 7.61 and 12.16 (mean, 9.49) and 0.009 and 0.015 (0.011), respectively. Total number of absolute differences ranged between 1 to 13 (average 5.76) between all members of this complex.

The presence of a very large minisatellite of $193 \mathrm{bp}$ long was detected tandemly repeated in all samples of the $T$. brasiliensis complex. This minisatellite area is of 386 bp long including two repeats of the minisatellite, located respectively between positions 213 and 405 and 406 and 598, of the alignment including all ITS- 1 haplotypes described. The two repetitions of this long minisatellite, are not identical in all 
Table 2

Geographic localities of the T. brasiliensis species complex analyzed, haplotypes obtained for rDNA ITS-1 and ITS-2 markers, and corresponding GenBank accession numbers.

\begin{tabular}{|c|c|c|c|c|c|c|c|c|c|c|c|c|c|c|}
\hline Species & State & Municipality & Coordinates & $\begin{array}{l}\text { Color } \\
\text { pattern* }\end{array}$ & $\begin{array}{l}\text { ITS-1 } \\
\text { haplotype }\end{array}$ & $\begin{array}{l}\text { Long } \\
\text { (bp) }\end{array}$ & $\begin{array}{l}\text { AT } \\
(\%)\end{array}$ & $\begin{array}{l}\text { ITS-2 } \\
\text { haplotipe }\end{array}$ & $\begin{array}{l}\text { Long } \\
\text { (bp) }\end{array}$ & $\begin{array}{l}\text { AT } \\
(\%)\end{array}$ & $\begin{array}{l}\text { Combined } \\
\text { haplotype }\end{array}$ & $\begin{array}{l}\text { Long } \\
\text { (bp) }\end{array}$ & $\begin{array}{l}\mathrm{AT} \\
(\%)\end{array}$ & $\begin{array}{l}\text { ITS-1, 5.8S, ITS-2 } \\
\text { GenBank Acc. No. }\end{array}$ \\
\hline $\begin{array}{l}\text { T. brasiliensis } \\
\text { (related) }\end{array}$ & Pernambuco & Salgadinho & $07^{\circ} 56^{\prime} 09^{\prime \prime} \mathrm{S} 35^{\circ} 37^{\prime} 58^{\prime \prime} \mathrm{W}$ & Bras/mac & ITS1-A & 837 & 61.89 & ITS2-2 & 478 & 78.24 & $\mathrm{CH} 2 \mathrm{~A}$ & 1470 & 65.10 & KJ125137 \\
\hline $\begin{array}{l}\text { T. brasiliensis } \\
\text { (related) }\end{array}$ & Pernambuco & Salgadinho & $07^{\circ} 56^{\prime} 09^{\prime \prime} \mathrm{S} 35^{\circ} 37^{\prime} 58^{\prime \prime} \mathrm{W}$ & $\mathrm{Mac} / \mathrm{br}$ & ITS1-A & 837 & 61.89 & ITS2-1 & 480 & 78.33 & $\mathrm{CH} 1 \mathrm{~A}$ & 1472 & 65.15 & KJ125136 \\
\hline $\begin{array}{l}\text { T. brasiliensis } \\
\text { (related) }\end{array}$ & Pernambuco & Garanhuns & $08^{\circ} 53^{\prime} 25^{\prime \prime} \mathrm{S} 36^{\circ} 29^{\prime} 34^{\prime \prime} \mathrm{W}$ & Mac/juaz & ITS1-C & 837 & 62.01 & ITS2-2 & 478 & 78.24 & $\mathrm{CH} 2 \mathrm{C}$ & 1470 & 65.17 & KJ125140 \\
\hline $\begin{array}{l}\text { T. brasiliensis } \\
\text { (related) }\end{array}$ & Pernambuco & Garanhuns & $08^{\circ} 53^{\prime} 25^{\prime \prime} \mathrm{S} 36^{\circ} 29^{\prime} 34^{\prime \prime} \mathrm{O}$ & Bras/dark & ITS1-C & 837 & 62.01 & ITS2-2 & 478 & 78.24 & $\mathrm{CH} 2 \mathrm{C}$ & 1470 & 65.17 & KJ125140 \\
\hline $\begin{array}{l}\text { T. brasiliensis } \\
\text { (related) }\end{array}$ & Pernambuco & Garanhuns & $08^{\circ} 53^{\prime} 25^{\prime \prime}$ S $36^{\circ} 29^{\prime} 34^{\prime \prime} \mathrm{w}$ & Bras/dark & ITS1-B & 837 & 62.01 & ITS2-1 & 480 & 78.33 & CH1B & 1472 & 65.22 & KJ125139 \\
\hline T. b. brasiliensis & Ceará & Tapera & $03^{\circ} 57^{\prime} 51^{\prime \prime} \mathrm{S} 38^{\circ} 21^{\prime} 00 \mathrm{~W}$ & Typical & ITS1-A & 837 & 61.89 & ITS2-3 & 482 & 78.42 & $\mathrm{CH} 3 \mathrm{~A}$ & 1474 & 65.20 & KJ125138 \\
\hline T. b. brasiliensis & Ceará & Tapera & $03^{\circ} 57^{\prime} 51^{\prime \prime} \mathrm{S} 38^{\circ} 21^{\prime} 00 \mathrm{~W}$ & Typical & ITS1-A & 837 & 61.89 & ITS2-3 & 482 & 78.42 & CH3A & 1474 & 65.20 & KJ125138 \\
\hline T. b. brasiliensis & Ceará & Tapera & $03^{\circ} 57^{\prime} 51^{\prime \prime} \mathrm{S} 38^{\circ} 21^{\prime} 00 \mathrm{~W}$ & Typical & ITS1-A & 837 & 61.89 & ITS2-3 & 482 & 78.42 & CH3A & 1474 & 65.20 & KJ125138 \\
\hline T. b. macromelasoma & Pernambuco & Petrolina/reared in lab. & $09^{\circ} 23^{\prime} 55^{\prime \prime} \mathrm{S} 40^{\circ} 30^{\prime} 03^{\prime \prime} \mathrm{W}$ & Typical & ITS1-D & 837 & 62.01 & ITS2-1 & 480 & 78.33 & CH1D & 1472 & 65.22 & KJ125141 \\
\hline T. b. macromelasoma & Pernambuco & Petrolina/reared in lab. & $09^{\circ} 23^{\prime} 55^{\prime \prime} \mathrm{S} 40^{\circ} 30^{\prime} 03^{\prime \prime} \mathrm{W}$ & Typical & ITS1-E & 837 & 62.13 & ITS2-1 & 480 & 78.33 & CH1E & 1472 & 65.29 & KJ125142 \\
\hline T. b. macromelasoma & Pernambuco & Petrolina/reared in lab. & $09^{\circ} 23^{\prime} 55^{\prime \prime} \mathrm{S} 40^{\circ} 30^{\prime} 03^{\prime \prime} \mathrm{W}$ & Typical & ITS1-G & 837 & 62.0 & ITS2-1 & 480 & 78.33 & $\mathrm{CH} 1 \mathrm{G}$ & 1472 & 65.22 & KJ125144 \\
\hline T. b. macromelasoma & Pernambuco & Petrolina/reared in lab. & $09^{\circ} 23^{\prime} 55^{\prime \prime} \mathrm{S} 40^{\circ} 30^{\prime} 03^{\prime \prime} \mathrm{W}$ & Typical & ITS1-F & 837 & 62.01 & ITS2-1 & 480 & 78.33 & $\mathrm{CH} 1 \mathrm{~F}$ & 1472 & 65.22 & KJ125143 \\
\hline T. b. macromelasoma & Pernambuco & Petrolina/reared in lab. & $09^{\circ} 23^{\prime} 55^{\prime \prime} \mathrm{S} 40^{\circ} 30^{\prime} 03^{\prime \prime} \mathrm{W}$ & Typical & ITS1-G & 837 & 62.01 & ITS2-1 & 480 & 78.33 & CH1G & 1472 & 65.22 & KJ125144 \\
\hline T. b. macromelasoma & Pernambuco & Petrolina/reared in lab. & $09^{\circ} 23^{\prime} 55^{\prime \prime} \mathrm{S} 40^{\circ} 30^{\prime} 03^{\prime \prime} \mathrm{W}$ & Typical & ITS1-E & 837 & 62.1 & ITS2-1 & 480 & 78.33 & CH1E & 1472 & 65.29 & KJ125142 \\
\hline T. b. macromelasoma & Pernambuco & Petrolina/reared in lab. & $09^{\circ} 23^{\prime} 55^{\prime \prime} \mathrm{S} 40^{\circ} 30^{\prime} 03^{\prime \prime} \mathrm{w}$ & Typical & ITS1-H & 837 & 62.01 & ITS2-1 & 480 & 78.33 & $\mathrm{CH} 1 \mathrm{H}$ & 1472 & 65.22 & KJ125145 \\
\hline T. b. macromelasoma & Pernambuco & Petrolina/reared in lab. & $09^{\circ} 23^{\prime} 55^{\prime \prime} \mathrm{S} 40^{\circ} 30^{\prime} 03^{\prime \prime} \mathrm{W}$ & Typical & ITS1-I & 837 & 62.13 & ITS2-1 & 480 & 78.33 & CH1I & 1472 & 65.29 & $\mathrm{KJ} 125146$ \\
\hline T. b. macromelasoma & Pernambuco & Petrolina/reared in lab. & $09^{\circ} 23^{\prime} 55^{\prime \prime} \mathrm{S} 40^{\circ} 30^{\prime} 03^{\prime \prime} \mathrm{W}$ & Typical & ITS1-I & 837 & 62.13 & ITS2-1 & 480 & 78.33 & $\mathrm{CH} 1 \mathrm{I}$ & 1472 & 65.29 & KJ125146 \\
\hline T. b. macromelasoma & Pernambuco & Salgadinho/reared in lab. & $09^{\circ} 24^{\prime} 50^{\prime \prime} \mathrm{S} 40^{\circ} 30^{\prime} 10^{\prime \prime} \mathrm{W}$ & Typical & ITS1-A & 837 & 61.89 & ITS2-1 & 480 & 78.33 & CH1A & 1472 & 65.15 & KJ125136 \\
\hline T. melanica & Bahia & Urandi/reared in lab. & $14^{\circ} 46^{\prime} 15^{\prime \prime} \mathrm{S} 42^{\circ} 39^{\prime} 18^{\prime \prime} \mathrm{W}$ & Typical & ITS1-J & 837 & 62.01 & ITS2-4 & 480 & 78.33 & $\mathrm{CH} 4 \mathrm{~J}$ & 1472 & 65.22 & KJ125147 \\
\hline T. melanica & Bahia & Urandi/reared in lab. & $\begin{array}{l}14^{\circ} 46^{\prime} 15^{\prime \prime} \mathrm{S} 42^{\circ} 39^{\prime} 18^{\prime \prime} \mathrm{W} \\
14^{\circ} 55^{\prime} 34^{\prime \prime} \mathrm{S}\end{array}$ & Typical & ITS1-J & 837 & 62.01 & ITS2-4 & 480 & 78.33 & $\mathrm{CH} 4 \mathrm{~J}$ & 1472 & 65.22 & KJ125147 \\
\hline T. melanica & Bahia & Urandi & $42^{\circ} 49^{\prime} 09^{\prime \prime} \mathrm{W}$ & Typical & ITS1-J & 837 & 62.01 & ITS2-4 & 480 & 78.33 & $\mathrm{CH} 4 \mathrm{~J}$ & 1472 & 65.22 & KJ125147 \\
\hline T. sherlocki & Bahia & Gentio do Ouro/reared in lab. & $11^{\circ} 25^{\prime} 44^{\prime \prime} \mathrm{S} 42^{\circ} 30^{\prime} 21^{\prime \prime} \mathrm{W}$ & Typical & ITS1-K & 837 & 62.13 & ITS2-5 & 480 & 78.54 & CH5K & 1472 & 65.36 & KJ125149 \\
\hline T. sherlocki & Bahia & Gentio do Ouro/reared in lab. & $11^{\circ} 25^{\prime} 44^{\prime \prime}$ S $42^{\circ} 30^{\prime} 21^{\prime \prime} \mathrm{W}$ & Typical & ITS1-K & 837 & 62.13 & ITS2-5 & 480 & 78.54 & CH5K & 1472 & 65.36 & KJ125149 \\
\hline T. sherlocki & Bahia & Gentio do Ouro/reared in lab. & $11^{\circ} 25^{\prime} 44^{\prime \prime} \mathrm{S} 42^{\circ} 30^{\prime} 21^{\prime \prime} \mathrm{W}$ & Typical & ITS1-L & 837 & 62.01 & ITS2-6 & 483 & 78.47 & CH6L & 1475 & 65.29 & KJ125148 \\
\hline T. juazeirensis & Bahia & Juazeiro & $09^{\circ} 24^{\prime} 50^{\prime \prime} \mathrm{S} 40^{\circ} 30^{\prime} 10^{\prime \prime} \mathrm{W}$ & Typical & ITS1-M & 836 & 62.20 & ITS2-8 & 477 & 78.35 & $\mathrm{CH} 8 \mathrm{M}$ & 1468 & 65.26 & KJ125150 \\
\hline T. juazeirensis & Bahia & Juazeiro/reared in lab. & $09^{\circ} 24^{\prime} 50^{\prime \prime} \mathrm{S} 40^{\circ} 30^{\prime} 10^{\prime \prime} \mathrm{W}$ & Typical & ITS1-N & 836 & 62.08 & ITS2-7 & 479 & 78.29 & CH7N & 1470 & 65.24 & KJ125151 \\
\hline T. juazeirensis & Bahia & Juazeiro/reared in lab. & $09^{\circ} 24^{\prime} 50^{\prime \prime}$ S $40^{\circ} 30^{\prime} 10^{\prime \prime} \mathrm{w}$ & Typical & ITS1-M & 836 & 62.20 & ITS2-8 & 477 & 78.35 & CH8M & 1468 & 65.26 & KJ125150 \\
\hline T. juazeirensis & Bahia & Juazeiro/reared in lab. & $09^{\circ} 24^{\prime} 50^{\prime \prime}$ S $40^{\circ} 30^{\prime} 10^{\prime \prime} \mathrm{W}$ & Typical & ITS1-M & 836 & 62.20 & ITS2-8 & 477 & 78.35 & CH8M & 1468 & 65.26 & KJ125150 \\
\hline
\end{tabular}

* According to the taxonomic key for all members of the complex (Costa et al., 2013). 


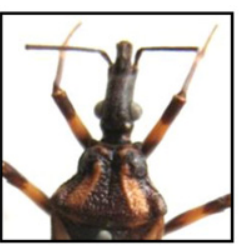

T. b. brasiliensis

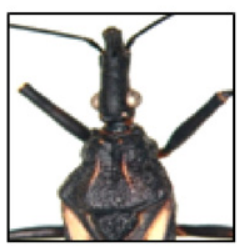

juaz mcfp

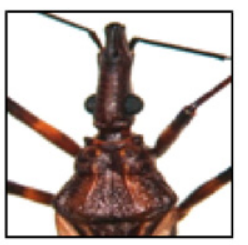

bras/bn

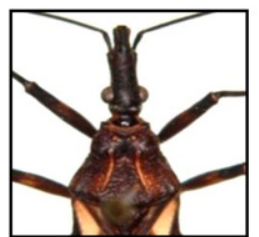

T. b. macromelasoma

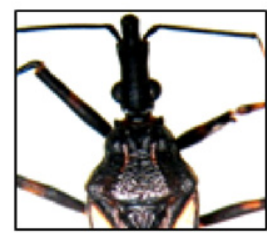

mac/jua

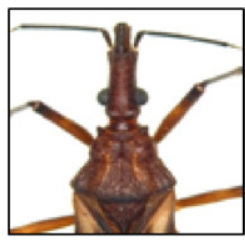

$\mathrm{mac} / \mathrm{bn}$

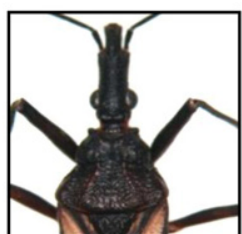

T. juazeirensis

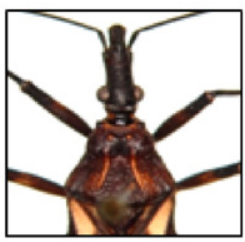

mac

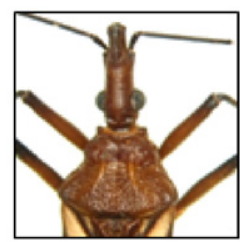

brown

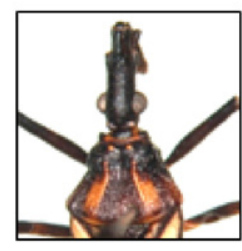

bras/mac

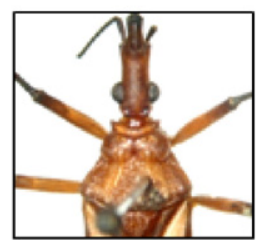

light brown

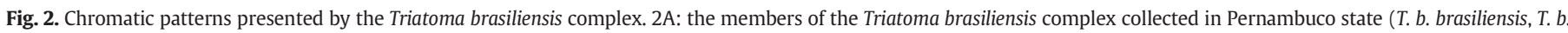
macromelasoma, T. juazeirensis); 2B: distinct chromatic phenotypes encountered in the state of Pernambuco.

ITS-1 haplotypes, providing a total of 9 variable positions of which, 7 were parsimony informative and 2 singleton sites.

\subsection{Second internal transcribed spacer ITS-2}

A total of 8 different ITS-2 haplotypes were detected among the samples analyzed and codified as ITS2-1 to ITS2-8. Length and AT content ranged between 477 and 485 bp (479.8 bp) and $78.20 \%-$ 78.54\% (78.35\%), respectively. The most frequent haplotype coexisting with ITS1-A in the same specimens was selected for H1. These eight ITS-2 haplotypes were compared with the only complete ITS-2 sequence of $T$. brasiliensis available in the GenBank (AJ293591; Marcilla et al., 2001) from Ceará, Brazil, showing close similarity with haplotypes of $T$. $b$. brasiliensis/T. $b$. macromelanosoma. The presence of a tandemly repeat minisatellite (TCTGC) in positions 380-384 in the ITS-2 alignment allows the distinction between populations from Ceará and all other states evaluated.

Haplotypes ITS2-1 to ITS2-3 were detected in samples of $T$. $b$. brasiliensis and T. $b$. macromelanosoma, being the most abundant the haplotype ITS2-1, present in the majority of specimens analyzed. Haplotype ITS2- 4 was detected in samples of T. melanica, haplotypes ITS2-5 and ITS2-6 in samples of $T$. sherlocki and haplotypes ITS2-7 and ITS2-8, in samples of T. juazeirensis (Tables 2, 3).

The 488 bp-long alignment including the nine ITS-2 haplotypes (T. brasiliensis complex ITS2-1 to ITS2-8 and T. brasiliensis AJ293591) generate the presence of a total of 16 variable positions $(3.27 \%)$ of which, 14 were indels (2.87\%), only 2 were mutations $(0.41 \%)$ and no parsimony informative position was detected. This very low degree of genetic differences, being in the majority only gapped positions, generate a very high similarity of the ITS- 2 sequences between all the members of the $T$. brasiliensis complex (Supplementary Table 1 ). Total number of absolute differences ranged between 0 to 2 (average 0.44 ) between all members of this complex.

As in the case of the ITS-1, three ITS-2 haplogroups corresponding to T.b. brasiliensis + T. b. macromelanosoma; T. melanica + T. sherlocki; and
T. juazeirensis have been considered and evaluated. Average number of absolute differences and p-distances between these haplogroups ranged between 0.250 and 0.583 (mean, 0.389) and 0.0005 and 0.0012 (0.0008), respectively.

\subsection{Phylogenetic and network analyses}

The ITS- 1 and ITS-2 combined haplotype network constructed using MJ network algorithm shows the existence of three discrete lineages: (i) a big group with a high diversity of haplotypes $(11 \mathrm{CH})$, including samples of $T$. $b$. brasiliensis and $T$. $b$. macromelanosoma from the states of Pernanbuco and Ceará, suggesting a gene flow or a close relationship between these two subspecies; (ii) a second group including haplotypes of T. melanica and T. sherlocki, both from Bahia; and (iii) one small group including the only two haplotypes of $T$. juazeirensis from Juazeiro in Bahia (Fig. 3). Only one haplotype (1A) was present in two members simultaneously (T. b. brasiliensis and T. b. macromelanosoma). Pernambuco and Ceará depict the highest number of haplotypes, but concentrated in only one of the lineages in the network, while Bahia depicts haplotypes in two distant lineages. This genetic diversity found in the first lineage, supports the consideration of haplotype $1 \mathrm{~A}$ as the ancestral one, because of its central location in the network, and its relationship with other derived haplotypes. Moreover, haplotype ITS-1A is present in a significant proportion of individuals coming from a wide geographic distribution, including several regions (Table 3).

Phylogenetic analyses were constructed using a total of $26 \mathrm{CH}$ of ITS- $1+5.8 \mathrm{~S}+$ ITS- 2 sequences including: $16 \mathrm{CH}$ provided by the members of $T$. brasiliensis complex, together with the complete intergenic region of: Triatoma sordida (AJ576063), T. infestans (AJ576051), T. platensis (AJ576061), T. delpontei (AJ576057) (Bargues et al., 2006); T. rubrovaria (AJ557258) (Pacheco et al., 2007); and Panstrongylus megistus (HF678458), P. herreri (AM949584, AJ306550); P. geniculatus (AM949585, AJ306543) (Marcilla et al., 2001; Mas-Coma and Bargues, 2009). The sequences of Mepraia spinolai FN396516 and Triatoma eratyrusiformis FN396537 (Calleros et al., 2010) were used as outgroups. 
Table 3

Polymorphic sites allowing differences between complete intergenic rDNA haplotypes of species and populations of T. brasiliensis complex analyzed from Brazil.

ITS1+ITS2 Members of T. brasiliensis Complex Color Pattern
Haplotype

\section{$1111222234 \quad 4556666777 \quad 7800023333 \quad 333$ \\ 567825680126645692266055564445556 \\ 730692146820327454517826707897898}

\begin{tabular}{|c|c|c|c|c|c|c|}
\hline $1-\mathrm{A}$ & T.b.brasiliensis, T.b.macromelanosoma & mac/br; typical (Tom) & CCATCCAGGC & CGGACACCAG & ATTAA-TTA- & $-\mathrm{TC}$ \\
\hline $2-\mathrm{A}$ & T.b.brasiliensis & bras/mac & $\ldots \ldots \ldots$ & $\ldots \ldots \ldots$ & $\ldots{ }^{---} \ldots-$ & $-\ldots$ \\
\hline $3-\mathrm{A}$ & T.b.brasiliensis & typical & $\ldots \ldots \ldots$ & $\ldots \ldots \ldots$ & $\ldots \ldots-\ldots \mathrm{A}$ & T. . \\
\hline $1-\mathrm{B}$ & T.b.brasiliensis & bras/dark & $\ldots \ldots \ldots$ & $\ldots \ldots \ldots$ & $\ldots \ldots-\ldots-$ & $-\ldots$ \\
\hline $2-\mathrm{C}$ & T.b.brasiliensis & mac/juaz; bras/dark & $\ldots \ldots \ldots$ & A........ & $\ldots--\ldots-$ & $-\ldots$ \\
\hline $1-D$ & T.b.macromelanosoma & typical & $\ldots$. . . & $\ldots \ldots \ldots$ & $\ldots \ldots-\ldots-$ & $-\ldots$ \\
\hline $1-E$ & T.b.macromelanosoma & typical & $\ldots \ldots \ldots \mathrm{T}$ & $\ldots$ A. . . . & $\ldots \ldots-\ldots-$ & $-\ldots$ \\
\hline $1-F$ & T.b.macromelanosoma & typical & $\ldots$. А... & $\ldots$ & $\ldots \ldots-\ldots-$ & $-\ldots$ \\
\hline $1-G$ & T.b.macromelanosoma & typical & $\ldots \ldots \ldots \mathrm{T}$ & $\ldots \ldots \ldots$ & $\ldots \ldots-\ldots-$ & $-\ldots$ \\
\hline $1-\mathrm{H}$ & T.b.macromelanosoma & typical & $\ldots \ldots \ldots$ & $\ldots A \ldots \ldots$ & $\ldots \ldots-\ldots-$ & $-\ldots$ \\
\hline $1-I$ & T.b.macromelanosoma & typical & $\ldots$ А.... & $\ldots$..... & $\ldots \ldots-\ldots-$ & $-\ldots$ \\
\hline $4-\mathrm{J}$ & T.melanica & typical & T...GAA & .T...... & $\mathrm{GA}-\ldots \mathrm{T} \ldots-\mathrm{A}$ & $\mathrm{T}-$. \\
\hline $5-K$ & T.sherlocki & typical & T...T.GAA &. $\mathrm{T} \ldots \mathrm{G} \ldots$ & $\mathrm{G} \ldots \mathrm{T} \ldots \mathrm{A}$ & T. . \\
\hline $6-\mathrm{L}$ & T.sherlocki & typical & T.....GAA &. T....... & G. $-\ldots$ T... &.$- \mathrm{A}$ \\
\hline $8-\mathrm{M}$ & T.juazeirensis & typical & TTCA..... & $\ldots-\ldots \mathrm{AAT}$ & $\ldots-\ldots---$. & - . \\
\hline $7-\mathrm{N}$ & T.juazeirensis & typical & TTCA..... & $\ldots-\ldots \mathrm{AT}$ & $\ldots-\ldots-\ldots-$ & $-\ldots$ \\
\hline
\end{tabular}

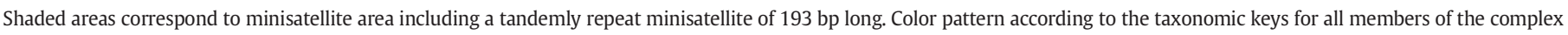
(Costa et al., 2013 submitted).

Position $=$ numbers (to be read in vertical) refer to variable positions obtained in the ITS-1 alignment made with MEGA 5.2. Identical $=$.; Indel $=-$.

The ML model best fitting this data set was HKY85 + I + G using the ti/tv ratio of 1.39 , base frequencies for $A, C, G$, and $T$ of $0.3550,0.1333$, 0.1614 and 0.3503 , respectively, proportion of invariable sites $=0.156$, and the gamma distribution $=3.23$. The resulting phylogeny $(-\operatorname{Ln}=$
7119.1284) was evaluated using least squares method with ML distances, showing high bootstrap values ( $>70$ for at least one criterion) supporting the reliability of the nodes corresponding to $T$. brasiliensis complex, infestans complex and rubrovaria subcomplex (Fig. 4A). Inside

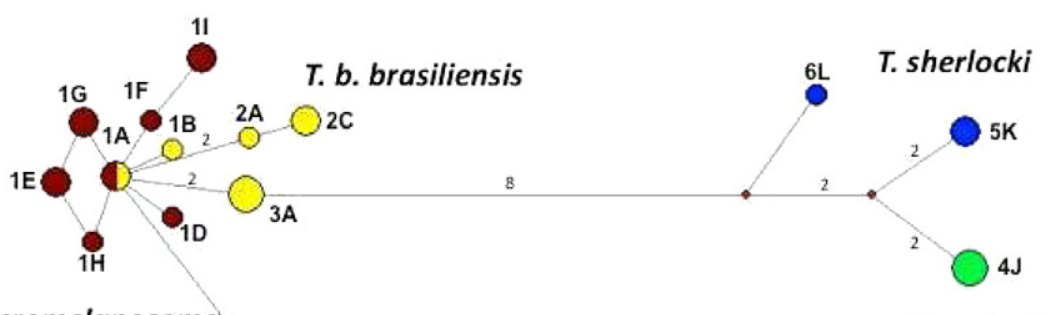

T. b. macromelanosoma

T. melanica

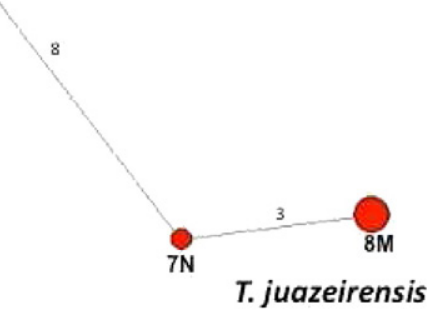

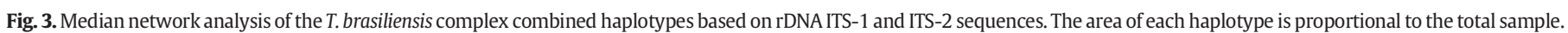

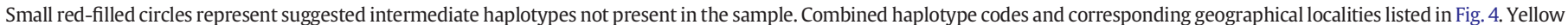

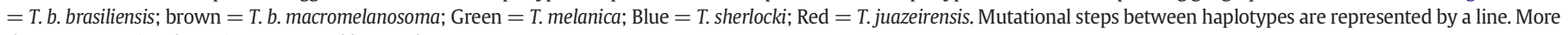
than one mutational step is represented by numbers. 


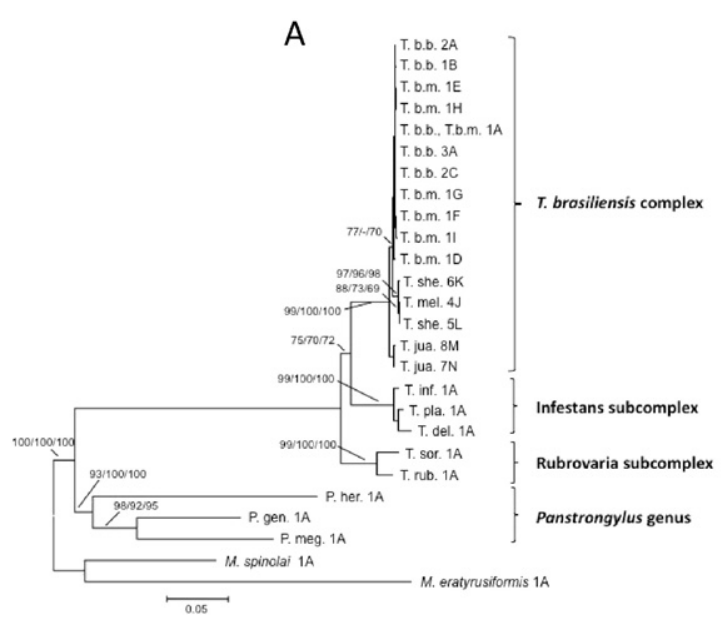

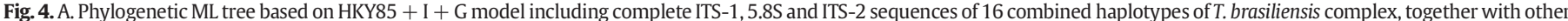

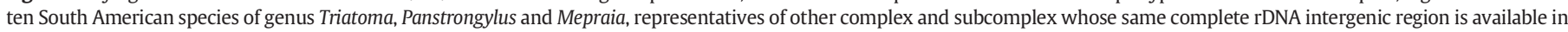

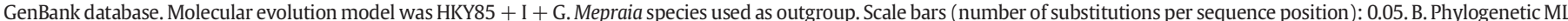

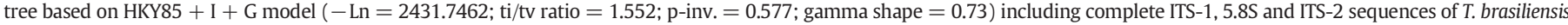

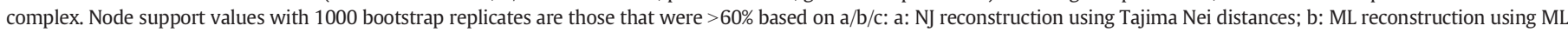

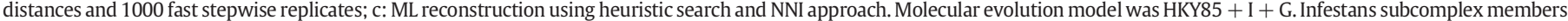
(T. infestans, T. platensis and T. delpontei) used as outgroup (not shown). Scale bar (number of substitutions per sequence position): 0.0005 .

the monophyletic clade comprising T. brasiliensis complex, tree subclades appear grouping $T$. b. brasiliensis and T. b. macromelasoma; T. sherlocki and T. melanica; and T. juazeirensis. The tree obtained using only species of the infestans complex as outgroup (Fig. 4B) shows that T. juazeirensis appears as sister species of the clade grouping all T. $b$. brasiliensis, T. b. macromelanosoma, T. sherlocki and T. melanica phenotypes and haplotypes analyzed. The topology of the clades was similar to that of the groupings obtained with the MJ network (Fig. 3).

\subsection{Relationships between genetic and phenetic distances}

The Mantel tests performed between the genetic (Tajima-Nei) and the phenetic (Jaccard, Hamann, Rogers-Tanimoto or Sokal-Michener) matrices of distances were significant (P ranging from 0.001 to 0.005 ). The highest level of correlation was obtained with the Jaccard's phenetic distances ( $r$ 0.38, r2 0.62).

\section{Discussion}

Pernambuco state, Brazil is situated between the distributional areas of $T$. b. brasiliensis (north) and T. juazeirensis (south), where it is occupied by T. b. macromelasoma (Costa et al., 2014). Based on (i) the greater chromatic variation of $T$. b. macromelasoma, (ii) morphometric geometrics (iii) and also considering the geographical position of occurrence of this subspecies in Pernambuco, Costa et al. (2009) proposed that this area might represent a zone of natural hybridization between $T$. b. brasiliensis and T. juazeirensis. Our results showed that T. b. macromelasoma displays greater chromatic variations within T. brasiliensis species complex, exhibiting intermediate chromatic phenotypes between the $T$. $b$. brasiliensis and $T$. juazeirensis. We conducted phylogenetic analyses using ribosomal DNA intergenic region under a Maximum Likelihood framework that grouped these phenotypes within the $T$. brasiliensis complex. Together with previous findings (Costa et al., 2009), results herein obtained supported the idea of a hybridization zone in Pernambuco state that gave rise to the T. b. macromelasoma through homoploidal evolution.

Laboratory crosses between $T$. b. brasiliensis, T. juazeirensis and T. macromelasoma generated fertile hybrid offspring (Costa et al., 2003b). This, combined with multiple morphological parameters and their geographical distributions, made possible the first thoughts concerning the hybridization between $T$. b. brasiliensis and $T$. juazeirensis as a mode to originate T. b. macromelasoma (Costa et al., 2009). This was the first time that hybridization was suggested to be a possible speciation mechanism in Triatominae. According to Galvão (1956), Petrolina, in the state of PE, represents the type locality and the original distribution of $T . b$. macromelasoma. In addition, its northern border correlates with the southernmost distribution of $T$. b. brasiliensis and its southern border with the northern most distribution of T. juazeirensis.

Coloration is one of the most variable characteristics and exists widely in natural populations of diverse insects (Gray and McKinnon, 2006). Specimens of the T. brasiliensis complex, which include T. $b$. brasiliensis, T. b. macromelasoma, T. melanica, T. sherlocki and T. juazeirensis, may be distinguished by their color patterns and genetic profiles (Monteiro et al., 2004; Costa et al., 2013). Variations, such as those observed in the T. brasiliensis complex, can be indicators of genetic drift and, within its geographic distribution, the highest phenotypic variability was observed in the state of PE (Monteiro et al., 2004). Areas of hybridization are expected to permit a greater combination of alleles that would consequently generate a greater variability in chromatic phenotypes in relation to other areas of the species (Rieseberg et al., 1999).

Thirteen distinct phenotypes of the T. brasiliensis complex were here defined according to the most evident chromatic traits for the 412 specimens collected in the PE before correlating to the capture sites. The greatest diversity in coloration was observed in the areas of Sertão do São Francisco and Sertão do Araripe where 11 and 12 phenotypes were collected, respectively. In the Agreste region, only 2 different phenotypes were identified. Even though the number of collected specimens cannot be considered as the expression of the absolute percentage for each phenotype, some indicative differences were observed in the three studied mesoregions of PE.

Nearly one third of the specimens collected in the São Francisco region had a color pattern related to T. b. macromelasoma, almost $30 \%$ presented a phenotype of mac/juaz and $12.59 \%$ presented a phenotype of juaz. The patterns suggest an influence of the T. juazeirensis chromatic phenotype, whose distribution borders the southern edge and is separated by São Francisco river. In the region of Sertão Araripe, the T. $b$. macromelasoma phenotype was reduced to $14.1 \%$ of the total and no specimens with a juaz phenotype were identified. The most common phenotype was mac/bn and the number of $T$. b. brasiliensis chromatic 
phenotypes was the greatest in specimens captured in this area. The third most collected phenotype was defined as brown (bn), which suggests a transgressive segregated phenotype since none of the parental characteristics were observed in these specimens (Rieseberg et al., 1999). In the Agreste region, the influence of the $T$. $b$. brasiliensis appeared most evident since both phenotypes were characterized as dark bras and bras/mac. The Sertão Araripe and Agreste regions both border the distribution of T. b. brasiliensis.

\subsection{Nuclear ribosomal DNA analyses}

It is the first time that a genetic analysis of the members of $T$. brasiliensis complex has been performed based on sequences of the complete ITS-1, 5.8S and ITS-2 rDNA intergenic region. Fourteen and eight haplotypes have been detected for each ITS- 1 and ITS- 2 spacers, respectively, and a total of sixteen combined haplotypes (ITS-1 + ITS2 ) for specimens representing 3 Brazilian states, 7 geographical localities and 9 color patterns.

The whole intergenic rDNA region provides a data set with an average length and AT content of $1471.7 \mathrm{bp}$ and $65.23 \%$, respectively. This region was considerably longer than the $1377 \mathrm{bp}$ described for T. rubrovaria (Pacheco et al., 2003, 2007), the 1375 bp of the infestans subcomplex (Bargues et al., 2006) and the $1371 \mathrm{bp}$ in the genus Mepraia (Calleros et al., 2010). The total of 16 combined haplotypes described for this intergenic region provides a genetic variability of $2.23 \%$ in the members of the $T$. brasiliensis complex analyzed, allowing for species and population differentiation. This genetic variability is similar to those obtained in the infestans subcomplex, suggesting evolving divergence processes presently ongoing within the species in question (Piccinali et al., 2011).

The ITS- 1 in $T$. brasiliensis complex proved to be markedly longer than ITS-2, and its bias in AT composition is lower than in ITS-2, as observed in other Triatominae (Bargues et al., 2006, 2008; Pacheco et al., 2007; Calleros et al., 2010).

Total variability obtained (considering total character differences $=$ indels and mutations) was $2.63 \%$ and $3.27 \%$ for the ITS- 1 and ITS-2, respectively. When only true mutations are considered, the percentages of genetic variability of both markers differed considerably, being of $2.51 \%$ and $0.41 \%$ for ITS- 1 and ITS-2, respectively. These results are in agreement with the molecular clock dating proposed for triatomines, according to which ITS-1 evolved 1.12-2.60 times faster than ITS-2 (Bargues et al., 2000, 2002, 2006). Without considering indels because of their weight lower than that of mutations, the number of transitions (ts) and transversions (tv) enables for a better species and population differentiation in the ITS- 1 than in the ITS- 2 in T. brasiliensis complex. It is known in other organisms that the coexistence of many indels with very few mutations usually indicates active evolutionary divergence processes (Bargues et al., 2001).

Only two mutations (tv) between ITS-2 sequences of all members of the $T$. brasiliensis complex have been detected. This reduced variability in the ITS-2 is in agreement with the chromosome homogeneity observed between the four chromatic members of $T$. brasiliensis complex (Panzera et al., 2000). A low variability in rDNA ITS-2 sequences has also been described in the phyllosoma complex (Marcilla et al., 2001; Bargues et al., 2002; Martínez et al., 2006; Martínez-Hernandez et al., 2010). For those Mexican species it was concluded that a subspecies status would fit best (Bargues et al., 2002), as such a low number of differences are typical in organisms able to hybridize (Mas-Coma and Bargues, 2009).

The pairwise comparisons performed in members of the T. brasiliensis complex, considering total number of absolute differences, ranged from 1 to 13 (average 5.76) and 0 to 2 (average 0.44 ) for ITS- 1 and ITS-2, respectively. These values were in agreement with the information capacity of the different DNA markers, related to the speed of their evolutionary rates (Bargues et al., 2006; Mas-Coma and Bargues, 2009).
The presence of a minisatellite of $193 \mathrm{bp}$ long tandemly repeated in the ITS- 1 is reported for first time in members of $T$. brasiliensis complex. It does not contain enough information for molecular species or subspecies distinction, but was able to differentiate T. melanica and $T$. sherlocki from the other unities of the complex. This minisatellite demonstrates expected changes during evolution. Each members had the same number of repeats, but could differ in the mutations detected in repeat 1 (5) and in repeat 2 (4). These observations suggest that the replication of the repeats occurred before the $T$. brasiliensis complex separated into the current species grouping with the individual mutations arising afterwards.

This long minisatellite repeat had not been reported previously in any other Triatoma species. It differs from those of 10 and 15 bp-long minisatellites tandemly repeated in the infestans subcomplex members, and able to distinguish between sylvatic and domestic populations of T. infestans (Bargues et al., 2006). In T. rubrovaria from Argentina, Uruguay and Brazil, the ITS- 1 includes another minisatellite of $31 \mathrm{bp}$ tandemly repeated two times which does not however discriminate the different populations of T. rubrovaria (Pacheco et al., 2003, 2007). The total variability of the ITS-2 provided by members of $T$. brasiliensis complex analyzed is relatively high (3.27\%) when compared to the small genetic diversity of $1.83 \%$ obtained in the phyllosoma complex (including Triatoma bassolsae, Triatoma longipennis, Triatoma mazzotti, Triatoma picturata, Triatoma pallidipennis and Triatoma phyllosoma) and lower that of $4.58 \%$ in the infestans subcomplex (including Triatoma infestans, Triatoma platensis and Triatoma delpontei) or that of 5.62\% in Triatoma dimidiata sl. (including all subspecies and excluding the species Triatoma sp. aff. Dimidiata) (Bargues et al., 2006, 2008).

In the case of the ITS-1, the genetic diversity of $2.63 \%$ obtained in the T. brasiliensis complex is very low when compared with the $10.87 \%$ detected in the infestans species subcomplex, but when only true mutations are considered (and not indels generated by microsatellites), results are very similar for both groups of species, being of $2.51 \%$ and 2.29\% for Triatoma brasiliensis complex and infestans subcomplex, respectively.

Both rDNA markers suggest that there are not enough genetic criteria to support different species inside this group. However, the detection of three haplogroups using the ITS- 1 and the ITS- 2 suggest that the $T$. brasiliensis group is composed by three genetically distinct forms referred to (i) T.b. brasiliensis/T. b. macromelanosoma; (ii) T. melanica and T. sherlocki, and (iii) T. juazeirensis, that present a total genetic divergence of $2.63 \%$ and $3.27 \%$, an interhaplogroup p-distance average values of 0.011 and 0.0008 , for ITS- 1 and ITS-2, respectively, and a pattern of percentage number of differences compatible with the existence of a species complex in a clear process of speciation. The reproductive capacity between these unities could be the cause that prevented complete speciation of these taxa, as reported in the case of $T$. dimidiata complex of species and subspecies (Bargues et al., 2008). However, as each member of $T$. brasiliensis species complex is fit in a particular environmental condition (Costa et al., 2014), it might be avoiding interbreeding events.

The genetic closeness obtained between $T$. sherlocki and T. melanica using the complete intergenic region of rDNA is coincident with the results obtained using two mtDNA markers (Cyt b and 16S). Molecular phylogenetic analyses suggest that $T$. sherlocki is a sister species of T. melanica, as supported by robust credibility rates of $98 \%$ (Mendonça et al., 2009, Gardim et al., 2014).

The grouping by analysis of ribosomal DNA sequences of $T$. $b$. macromelasoma with $T$. b. brasiliensis confirms that both are close evolutionary unities, which was evidenced by low genetic distances among taxa. Phylogenetic results provided higher resolution for the distinction of T. b. brasiliensis + T. b. macromelanosoma, T. melanica, T. sherlocki and T. juazeirensis as independent evolutionary unities. The position of T. melanica and T. juazeirensis in the ML tree further suggests geographic separation between species as an important factor increasing genetic 
differences, in agreement with results with Cyt B sequences (Monteiro et al., 2004).

In general, a good correlation between phenotype and genotype have been observed, although previous studies reported some phenotypes intermediate between bra and mac, as well as some specimens presenting mac and jua phenotypes that clustered with bra in the DNA sequence analyses (Costa et al., 2009). Our results clearly agree with the results obtained with a fragment of the Cytb gene of the mtDNA (Monteiro et al., 2004), in the sense that rDNA genetic distances also separate members of the T. brasiliensis complex, especially the "typical" color patterns (Costa et al., 2013) as for T. b. brasiliensis + T. b. macromelanosoma, T. melanica $+T$. sherlocki and T. juazeirensis.

The high degree of chromatic variations, along with the correlations of genetic and phenetic distances through Mantel test, supported to the idea of a natural hybridization zone for the speciation of $T$. $b$. macromelasoma in Pernambuco state. However, these evidences are not conclusive, because ITS 1 and ITS 2 sequences may have not the resolution to point out the hybrid genetic profile evidenced by the intermediate phenotypes between the T, brasiliensis and T. juazeirensis. The observed fertile experimental hybrids between $T$. b. brasiliensis and T. juazeirensis demonstrate the potential for viability of these offspring in nature (Costa et al., 2003b). For other taxa, as members of the Phyllosoma complex in the Yucatan Peninsula in Mexico, viable lab-hybrids could have been produced (Martinez-Ibarra et al., 2009) and also indicated areas of natural hybridization events (HerreraAguilar et al., 2009).

Other aspects of triatomine biology that lend support to hybridization leading to speciation are the evidence of rapid evolution and the model of ecological niches. It is known that ecological traits are crucial to permit a species to maintain its distinctive traits with different species of triatomine having population dynamics that peak at different times during the year (Lucena, 1960). It has been proposed that the differentiation of T.b. macromelasoma was achieved due to a distinctive ecology compared to the other members of the complex (Costa et al., 2002, 2014). In this scenario, despite the apparent overlap in distributions, T. b. macromelasoma could be in an ecological niche isolated from the proposed parental species in a way that its differentiation can be maintained (Costa et al., 2009).

The state of PE is under strong environmental impact from increases in agricultural activity and human population growth. This can create greater pressure and increasing the chances of crosses between $T$. $b$. brasiliensis, $T$. juazeirensis and T. b. macromelasoma is through new mechanisms of transport and altering the natural habitats. Another similar scenario for T. juazeirensis and T. sherlocki must be further investigated because their distributional boundaries are unknown (Almeida et al., 2012) in an area now getting impacted by mining activities (Almeida et al., 2009). In addition to that, the T. cruzi susceptibility of hybrid specimens is very poorly understood, some previous results on the $T$. dimidiata were presented by Herrera-Aguilar et al. (2009), although recent clues in this sense have been provided for members of $T$. brasiliensis species complex (Costa et al., 2015).

In this study, 13 phenotypes of the T. brasiliensis complex were for the first time recorded in several sites of the PE state, compatible with the hypothesis of the existence of a natural hybrid zone for members of that complex, specifically: T. b. macromelasoma, T. b. brasiliensis, and T. juazeirensis are supposed to be involved. Also, an important fact is that all the recorded phenotypes were kept under the same laboratory conditions (data not published yet) and the heredity, homogeneity and stability of the different color patterns were confirmed. Finally, an important question arises related to whether an epigenetic phenomenon (Rieseberg et al., 1999; Liu and Wendel, 2003; Rieseberg and Willis, 2007) could also be involved in the morphological diversity of the $T$. brasiliensis complex is still to be assessed. This research is crucial to better understand the speciation process of the Triatominae group and brings relevant questions that relates also to the vectorial capacity. Arguments for an evolutionary significance of phenotypic variability were discussed by Dujardin et al. (2009) and epigenetics phenomenon was suggested for the Triatominae group and, results in the present study are also supportive of that phenomenon.

The successful campaign against $T$. infestans, previously the predominant cause of $T$. cruzi infections in humans, has elevated the importance of members of the T. brasiliensis complex due to their capacity to maintain and transmit T. cruzi. Improving the knowledge of each member of the $T$. brasiliensis complex, including their characterization and originating process, are important aspects for monitoring Chagas disease vector transmission.

Supplementary data to this article can be found online at http://dx. doi.org/10.1016/j.meegid.2015.10.025.

\section{Acknowledgments}

Study was funded by projects: RICET (RD12/0018/0013 of RETICS), VI National Plan of I + D + I 2008-2011, ISCIII - Subdirección General de Redes y Centros de Investigación Coopetariva and FEDER, Ministry of Health, Spain; and PROMETEO/2012/042, Programa de Ayudas para Grupos de Investigación de Excelencia, Generalitat Valenciana, Valencia, Spain. Technical support provided by the Servicio Central de Secuenciación para la Investigación Experimental (SCSIE) of the University of Valencia, Spain. Supported by Conselho Nacional de Desenvolvimento Científico e Tecnológico, CNPq (DCR fellowship program) and Fundação de Amparo a Pesquisa do Estado de São Paulo, FAPESP, process numbers 2010/17027-0 and 2011/22378-0.

\section{References}

Adams, D.C., Berns, C.M., Kozak, K.H., Wiens, J.J., 2009. Are rates of species diversification correlated with rates of morphological evolution? Proc. R. Soc. Lond. B 276, 2729-2738.

Akaike, H., 1974. A new look at the statistical model identification. IEEE Trans. Autom. Control 19, 716-723.

Almeida, C.E., Folly-Ramos, E., Peterson, A.T., Lima-Neiva, V., Gumiel, M., Duarte, R., Lima, M.M., Locks, M., Beltrão, M., Costa, J., 2009. Could the bug Triatoma sherlocki be vectoring Chagas disease in small mining communities in Bahia, Brazil? Med. Vet. Entomol. 23, 410-417.

Almeida, C.E., Oliveira, H.L., Correia, N., Dornak, L.L., Gumiel, M., Neiva, V.L., et al., 2012 Dispersion capacity of Triatoma sherlocki, Triatoma juazeirensis and laboratory-bred hybrids. Acta Trop. 122, 71-79.

Almeida, C.E., Pacheco, R.S., Haag, K., Dupas, S., Dotson, E., Costa, J., 2008. Inferring from the cyt B gene the Triatoma brasiliensis Neiva, 1911 (Hemiptera: Reduviidae: Triatominae). Genetic structure and domiciliary infestation in the state of Paraíba, Brazil. Am.J.Trop. Med. Hyg. 78, 791-802.

Almeida, C.E., Pacheco, R.S., Noireau, F., Costa, J., 2002. Triatoma rubrovaria (Blanchard, 1843) (Hemiptera: Reduviidae) I: Isoenzymatic and Chromatic Patterns of five populations from the State of Rio Grande do Sul, Brazil. Mem. Inst. Oswaldo Cruz 97, 829-834.

Bargues, M.D., Mas-Coma, S., 1997. Phylogenetic analysis of lymnaeid snails based on $18 \mathrm{~S}$ rDNA sequences. Mol. Biol. Evol. 14, 569-577.

Bargues, M.D., Klisiowicz, D.R., Gonzalez-Candelas, F., Ramsey, J.M., Monroy, C., Ponce, C., Salazar-Schettino, P.M., Panzera, F., Abad-Franch, F., Sousa, O.E., Schofield, C.J., Dujardin, J.P., Guhl, F., Mas-Coma, S., 2008. Phylogeography and genetic variation of Triatoma dimidiata, the main Chagas disease vector in Central America, and its position within the genus Triatoma. PLoS Negl. Trop. Dis. 2, e233.

Bargues, M.D., Klisiowicz, D.R., Panzera, F., Noireau, F., Marcilla, A., Perez, R., Rojas, M.G O'Connor, J.E., Gonzalez-Candelas, F., Galvao, C., Jurberg, J., Carcavallo, R.U. Dujardin, J.P., Mas-Coma, S., 2006. Origin and phylogeography of the Chagas disease main vector Triatoma infestans based on nuclear rDNA sequences and genome size. Infect. Genet. Evol. 6, 46-62.

Bargues, M.D., Marcilla, A., Dujardin, J.P., Mas-Coma, S., 2002. Triatomine vectors of Trypanosoma cruzi: a molecular perspective based on nuclear ribosomal DNA markers. Trans. R. Soc. Trop. Med. Hyg. 96, 159-164.

Bargues, M.D., Marcilla, A., Ramsey, J.M., Dujardin, J.P., Schofield, C.J., Mas-Coma, S., 2000 Nuclear rDNA-based molecular clock of the evolution of Triatominae (Hemiptera: Reduviidae), vectors of Chagas disease. Mem. Inst. Oswaldo Cruz 95, 567-573.

Bargues, M.D., Vigo, M., Horak, P., Dvorak, J., Patzner, R.A., Pointier, J.P., Jackiewicz, M., Meier-Brook, C., Mas-Coma, S., 2001. European Lymnaeidae (Mollusca: Gastropoda), intermediate hosts of trematodiases, based on nuclear ribosomal DNA ITS-2 sequences. Infect. Genet. Evol. 16, 1-23.

Bargues, M.D., Zuriaga, M.A., Mas-Coma, S., 2014. Nuclear rDNA pseudogenes in Chagas disease vectors: Evolutionary implications of a new 5.8S + ITS-2 paralogous sequence marker in triatomines of North, Central and northern South America. Infect. Genet. Evol. 21, 134-156.

Calleros, L., Panzera, F., Bargues, M.D., Monteiro, F.A., Klisiowicz, D.R., Zuriaga, M.A., Mas-Coma, S., Perez, R., 2010. Systematics of Mepraia (Hempitera - Reduviidae) cytogenetic and molecular variation. Infect. Genet. Evol. 10, 221-228. 
Correia, N., Almeida, C.E., Lima-Neiva, V., Gumiel, M., Dornak, L., Lima, M.M., Medeiros, L.M.O., Mendonça, V.J., da Rosa, J.A., Costa, J., 2013. Cross-mating experiments detect reproductive compatibility between Triatoma sherlocki and other members of the Triatoma brasiliensis species complex. Acta Trop. 128, 162-167.

Costa, J., Felix, M., 2007. Triatoma juazeirensis sp. nov. from the state of Bahia, Northeastern Brazil (Hemiptera: Reduviidae: Triatominae). Mem. Inst. Oswaldo Cruz 102, 87-90.

Costa, J., Almeida, C.E., Dotson, E., Lins, A., Vinhaes, M.C., Silveira, A.C., Beard, C.B., 2003a. The epidemiologic importance of Triatoma brasiliensis as a Chagas disease vector in Brazil: a revision of domiciliary captures during 1993-1999. Mem. Inst. Oswaldo Cruz 98, 443-449.

Costa, J., Almeida, C.E., Dujardin, J.P., Beard, C.B., 2003b. Crossing experiments detect genetic incompatibility among populations of Triatoma brasiliensis Neiva, 1911 (Heteroptera Reduviidae, Triatominae). Mem. Inst. Oswaldo Cruz 98, 637-639.

Costa, J., Almeida, J.R., Britto, C., Duarte, R., Marchon-Silva, V., Pacheco, R.S., 1998 Ecotopes, natural, infection and trophic resources of Triatoma brasiliensis (Hemiptera, Reduviidae, Triatominae). Mem. Inst. Oswaldo Cruz 93, 7-13.

Costa, J., Araújo, C.A.C., Freitas, C., Borges-Pereira, J., 2015. Are members of the Triatoma brasiliensis (Hemiptera, Reduviidae) species complex able to alter the biology and virulence of a Trypanosoma cruzi strain? Neotrop. Entomol. 1, 1-8.

Costa, J., Argolo, A.M., Felix, M., 2006. Redescription of Triatoma melanica Neiva Lent, 1941 new status (Hemiptera: Reduviidae: Triatominae). Zootaxa 1385, 47-52.

Costa, J., Barth, O.M., Marchon-Silva, V., Almeida, C.E., Freitas-Sibajev, M.G., Panzera, F. 1997a. Morphological, studies on the Triatoma brasiliensis Neiva, 1911 (Hemiptera, Reduviidae, Triatominae) - genital, structures and eggs of different chromatic forms. Mem. Inst. Oswaldo Cruz 92, 493-498.

Costa, J., Correia, N.C., Neiva, V.L., Goncalves, T.C.M., Felix, M., 2013. Revalidation and redescription of Triatoma brasiliensis macromelasoma Galvão, 1956 and an identification key for the Triatoma brasiliensis complex (Hemiptera: Reduviidae: Triatominae). Mem. Inst. Oswaldo Cruz 108, 785-789.

Costa, J., Dornak, L., Almeida, C.E., Peterson, A.T., 2014. Distributional potential of the Triatoma brasiliensis species complex at present and under scenarios of future climate conditions. Parasit. Vectors 7, 238-248.

Costa, J., Freitas-Sibajev, M.G., Marchon-Silva, V., Pires, M.Q., Pacheco, R., 1997b. Isoenzimes detect variation in populations of Triatoma brasiliensis (Hemiptera-ReduviidaeTriatominae). Mem. Inst. Oswaldo Cruz 92, 459-464.

Costa, J., Peterson, A.T. Beard, C.B. 2002. Ecological, niche modeling and differentiation of populations of Triatoma brasiliensis Neiva, 1911, the most important Chagas disease vector in Northeastern Brazil. Am.J.Trop. Med. Hyg. 67, 516-520.

Costa, J., Peterson, A.T., Dujardin, J.P., 2009. Morphological, evidence suggests homoploid hybridization as a possible mode of speciation in the Triatominae (Hemiptera Heteroptera, Reduviidae). Infect. Genet. Evol. 9, 263-270.

Dujardin, J.P., Costa, J., Bustamante, D., Jaramillo, N., Catalá, S., 2009. Deciphering morphology in Triatominae: the evolutionary signals. Acta Trop. 110, 101-111.

Galvão, A.B., 1956. Triatoma brasiliensis macromelasoman. subsp. (Hemiptera, Reduviidae). Rev. Bras. Malariol. Doencas Trop. 7, 455-457.

Gardim, S., Almeida, C.E., Takiya, D.M., Oliveira, J., Araujo, R.F., Cicarelli, R.M., et al., 2014 Multiple mitochondrial genes of some sylvatic Brazilian Triatoma: non-monophyly of the T. brasiliensis subcomplex and the need for a generic revision in the Triatomini. Infect. Genet. Evol. 23, 74-79.

Gray, S.M., McKinnon, J.S., 2006. Linking color polymorphism maintenance and speciation. Trends Ecol. Evol. 22, 71-79.

Gumiel, M., Catalá, S., Noireau, F., Arias, A.R., Garcia, A., Dujardin, J.P., 2003. Wing geometry in Triatoma infestans (Klug) and T. melanosona Martinez, Olmedo and Carcavallo (Hemiptera:Reduviidae). Syst. Entomol. 28, 173-180.

Herrera-Aguilar, M., Be-Barragan, L.A., Ramirez-Sierra, M.J., Tripet, F., Dorn, P., Dumonteil, E., 2009. Identification of a large hybrid zone between sympatric sibling species of Triatoma dimidiata in the Yucatan peninsula, Mexico, and its epidemiological importance. Infect. Genet. Evol. 9, 1345-1351.

Larkin, M., Blackshields, G., Brown, N., Chenna, R., McGettigan, P., McWilliam, H., Valentin, F., Wallace, I.M., Wilm, A., Lopez, R., Thompson, J.D., Gibson, T.J., Higgins, D.G., 2007. Clustal W and Clustal X version 2.0. Bioinformatics 23, 2947-2948.

Lent, H., Wygodzinsky, P., 1979. Revision of the triatominae (Hemiptera Reduviidae) and their significance as vectors of Chagas' disease. Bull. Am. Mus. Nat. Hist. 163, 123-520.

Lent, H., Jurberg, J., Galvão, C., Carcavallo, R.U., 1994. Triatoma melanosoma, novo status para Triatoma infestans melanosoma Martínez, Olmedo and Carcavallo, 1987. Mem. Inst. Oswaldo Cruz 89, 353-358.

Liu, B., Wendel, J.F., 2003. Epigenetic phenomena and the evolution of plant allopolyploids. Mol. Phylogenet. Evol. 29, 365-379.

Lucena, D.T., 1960. Evolução do "Triatoma brasiliensis" Neiva, 1911 no laboratório. Rev. Bras. Biol. 20, 295-302.

Marcilla, A., Bargues, M.D., Ramsey, J.M., Magallón-Gastélum, E., Salazar-Schettino, P.M. Abad-Franch, F., Dujardin, J.P., Schofield, C.J., Mas-Coma, S., 2001. The ITS-2 of the nuclear rDNA as a molecular marker for populations, species, and phylogenetic relationships in Triatominae (Hemiptera: Reduviidae), vectors of Chagas disease. Mol. Phylogenet. Evol. 18, 136-142.

Martínez, F.H., Villalobos, G.C., Cevallos, A.M., Torre, P.D., Laclette, J.P., Alejandre-Aguilar, R., Espinoza, B., 2006. Taxonomic study of the Phyllosoma complex and othe triatomine (Insecta: Hemiptera: Reduviidae) species of epidemiological importance in the transmission of Chagas disease: using ITS-2 and mtCytB sequences. Mol. Phylogenet. Evol. 41, 279-287.

Martínez-Hernandez, F., Martínez-Ibarra, J.A., Catalá, S., Villalobos, G., de la Torre, P., Laclette, J.P., Alejandre-Aguilar, R., Espinoza, B., 2010. Natural crossbreeding between sympatric species of the phyllosoma complex (Insecta: Hemiptera: Reduviidae) indicate the existence of only one species with morphologic and genetic variations. Am.J.Trop. Med. Hyg. 82, 74-82.

Martinez-Ibarra, J.A., Salazar-Schettino, P.M., Nogueda-Torres, B., Vences, M.O., TapiaGonzalez, J.M., Espinoza-Gutierrez, B., 2009. Occurrence of hybrids and laboratory evidence of fertility among three species of the Phyllosoma complex (Hemiptera: Reduviidae) in Mexico. Mem. Inst. Oswaldo Cruz 104, 1125-1131.

Mas-Coma, S., Bargues, M.D., 2009. Populations, hybrids and the systematic concepts of species and subspecies in Chagas disease triatomine vectors inferred from nuclear ribosomal and mitochondrial DNA. Acta Trop. 110,112-136.

Mendonça, V.J., Silva, M.T., Araújo, R.F., Júnior, J.M., Júnior, M.B., Almeida, C.E., Costa, J., Graminha, M.A., Cicarelli, R.M., Rosa, J.A., 2009. Phylogeny of Triatoma sherlocki (Hemiptera: Reduviidae: Triatominae) inferred from two mitochondrial genes suggests its location within the Triatoma brasiliensis complex. Am.J.Trop. Med. Hyg. $81,858-864$

Monteiro, F.A., Costa, J., Solé-Cava, A.M., 1999. Genetic confirmation of the specific status of Triatoma petrochii (Hemiptera: Reduviidae: Triatominae). Ann. Trop. Med. Parasitol. 92, 897-900.

Monteiro, F.A., Donnelly, M.J., Beard, C.B., Costa, J., 2004. Nested clade and phylogeographic analyses of the Chagas disease vector Triatoma brasiliensis in Northeast Brazil. Mol. Phylogenet. Evol. 32, 46-56.

Myers, E.W., Miller, W., 1988. Optimal alignments in linear space. Comput. Appl. Biosci. 4, 11-17.

Neiva, A., Lent, H., 1941. Sinopse dos triatomineos Rev. Entomol. 12, 62-92.

Neiva-Lima, V., Gumiel, M.X., Lima, M.M., Gonçalves, T.C.M., Provance, D.W., Almeida, C.E., Costa, J., 2012. Deposition, incubation period and hatching of eggs from Triatoma juazeirensis Costa \& Felix and Triatoma sherlocki Papa, Jurberg, Carcavallo, Cerqueira \& Barata (Hemiptera: Reduviidae) under laboratory conditions. EntomoBrasilis 7, 130-136.

Pacheco, R.S., Almeida, C.E., Costa, J., Klisiowicz, D.R., Mas-Coma, S., Bargues, M.D., 2003. RAPD analyses and rDNA intergenic-spacer sequences discriminate Brazilian populations of Triatoma rubrovaria (Reduviidae: Triatominae). Ann. Trop. Med. Parasitol. 97, 757-768.

Pacheco, R.S., Almeida, C.E., Klisiowicz, D.R., Costa, J., Pires, M.Q., Bar, M.E., Mas-Coma, S., Bargues, M.D., 2007. Genetic variability of Triatoma rubrovaria (Reduviidae: Triatominae) from Brazil, Argentina and Uruguay as revealed by two different molecular markers. Parasite 14, 231-237.

Panzera, F., Perez, R., Nicolini, P., Hornos, S., Costa, J., Borges, E., Diotaiuti, L., Schofield, C.J., 2000. Chromosome homogeneity in populations of Triatoma brasiliensis Neiva 1911 (Hemiptera - Reduviidae - Triatominae). Cad. Saúde Pública 16, 83-88.

Papa, A.R., Jurberg, J., Carcavallo, R.U., Cerqueira, R.L., Barata, J.M.S., 2002. Triatoma sherlocki sp. n. coletada na Bahia, Brasil (Hemiptera, Reduviidae, Triatominae). Entomologya and Vectores 9, 133-146.

Piccinali, R.V., Marcet, P.L., Ceballos, L.A., Kitron, U., Gürtler, R.E., Dotson, E.M., 2011. Genetic variability, phylogenetic relationships and gene flow in Triatoma infestans dark morphs from the Argentinean Chaco. Infect. Genet. Evol. 11, 895-903.

Pires, H.H.R., Barbosa, S.H., Jurberg, J., Diotaiuti, L., 1995. Comparative studies of distinct populations of Triatoma infentans. V. Morphological patterns of the male genitalia. Mem. Inst. Oswaldo Cruz 90, 227.

Posada, D., 2008. jModelTest: phylogenetic model averaging. Mol. Biol. Evol. 25, 1253-1256.

Posada, D., Buckley, T.R., 2004. Model selection and model averaging in phylogenetics: advantages of the AIC and Bayesian approaches over likelihood ratio tests. Syst. Biol. 53, 793-808.

Rieseberg, L.H., Archer, M.A., Wayne, R.K., 1999. Transgressive segregation, adaptation and speciation Heredity. 83, 363-372.

Rieseberg, L.H., Willis, J.H., 2007. Plant speciation. Science 317, 910-914.

Rieseberg, L.H., Archer, M.A., Wayne, R.K., 1999. Transgressive segregation, adaptation and speciation. Heredity 83, 363-372.

Silveira, A.C., Vinhaes, M.C., 1999. Elimination of vector-borne transmission of Chagas disease. Mem. Inst. Oswaldo Cruz 94, 405-411.

Swofford, D.L., 2002. PAUP*: Phylogenetic Analysis Using Parsimony (*and Other Methods). Version 4. Computer Program Distributed by the Smithsonian Institution. Sinauer Associates, Inc., Sunderland, MA.

Tajima, F., Nei, M., 1984. Estimation of evolutionary distance between nucleotide sequences. Mol. Biol. Evol. 1, 269-285.

Tamura, K., Peterson, D., Peterson, N., Stecher, G., Nei, M., Kumar, S., 2011. MEGA5: molecular evolutionary genetics analysis using maximum likelihood, evolutionary distance, and maximum parsimony methods. Mol. Biol. Evol. 28, 2731-2739. 